\title{
Monitoring neurocognitive functioning in childhood cancer survivors: evaluation of CogState computerized assessment and the Behavior Rating Inventory of Executive Function (BRIEF)
}

Lyn M. Balsamo ${ }^{1 *}$ (D), Hannah-Rose Mitchell ${ }^{2}$, Wilhelmenia Ross ${ }^{1}$, Catherine Metayer ${ }^{3}$, Kristina K. Hardy ${ }^{4,5}$ and Nina S. Kadan-Lottick ${ }^{1,6}$

\begin{abstract}
Background: Many childhood cancer survivors develop neurocognitive impairment, negatively affecting education and psychosocial functioning. Recommended comprehensive neuropsychological testing can be time- and costintensive for both institutions and patients and their families. It is important to find quick and easily administered surveillance measures to identify those in need of evaluation.

Methods: We evaluated, individually and in combination, the sensitivity and specificity of the 1) Behavior Rating Inventory of Executive Functioning-Metacognition Index (BRIEF-MCI), and 2) CogState Composite Index (computerized assessment of cognition) in identifying below grade-level performance on state-administered tests of reading and mathematics among childhood cancer survivors.

Results: The 45 participants (39\% female) were a mean age of $7.1 \pm 4.4$ years at diagnosis, $14.0 \pm 3.0$ at evaluation, with a history of leukemia (58\%), lymphoma (9\%), central nervous system tumors (20\%), and other tumors (13\%). Impairment on the BRIEF-MCI was associated with low sensitivity (26\% reading, $41 \%$ mathematics) but stronger specificity (88\% reading, 96\% mathematics). We found similar associations for the CogState Composite Index with sensitivity of $26 \%$ for reading and $29 \%$ for mathematics and specificity of $92 \%$ for both reading and mathematics. Combining the two measures did not improve sensitivity appreciably (47\% reading, 59\% mathematics) while reducing specificity (84\% reading, $88 \%$ mathematics).

Conclusions: While individuals identified from the BRIEF-MCI or CogState Composite would likely benefit from a full neuropsychological evaluation given the strong specificity, use of these measures as screening tools is limited. With poor sensitivity, they do not identify many patients with academic difficulties and in need of a full neuropsychological evaluation. Continued effort is required to find screening measures that have both strong sensitivity and specificity.
\end{abstract}

Keywords: Late effects, Neurocognitive, Neuropsychological evaluation, Computerized assessment, Survivorship

\footnotetext{
* Correspondence: lyn.balsamo@yale.edu

Presentations: Portions of this paper were originally presented at the

International Society of Paediatric Oncology (SIOP), Cape Town, South Africa,

October 2015.

'Yale University School of Medicine, 15 PO Box 208064, 16333 Cedar Street,

LMP-2073 (for courier mail), 17, New Haven, CT 06520-8064, USA

Full list of author information is available at the end of the article
}

(c) The Author(s). 2019 Open Access This article is distributed under the terms of the Creative Commons Attribution 4.0 International License (http://creativecommons.org/licenses/by/4.0/), which permits unrestricted use, distribution, and

reproduction in any medium, provided you give appropriate credit to the original author(s) and the source, provide a link to the Creative Commons license, and indicate if changes were made. The Creative Commons Public Domain Dedication waiver (http://creativecommons.org/publicdomain/zero/1.0/) applies to the data made available in this article, unless otherwise stated. 


\section{Background}

More than $80 \%$ of children and adolescents diagnosed with cancer survive their disease. [1] Curative therapies are often neurotoxic and can be associated with neurocognitive difficulties. [2] The Children's Oncology Group (COG) Long-Term Follow-Up Guidelines recommend routine surveillance for any pediatric cancer survivor at high risk for neurocognitive impairment. [3] [4, 5] [6] Unfortunately, traditional neuropsychological assessment is often timeand cost-intensive for patients and their families. Insurance reimbursement for evaluations is not uniform, even within the United States. [7] Further, evaluations typically require expertise in psychological testing that is not readily available at all pediatric cancer treatment centers. [8] In this context, comprehensive neurocognitive assessment for every child is ideal, but may not be a feasible goal. Therefore, efficient and accessible surveillance measures to identify children requiring comprehensive assessment are important to standard survivorship care. [9]

To achieve a better balance between needs, patient costs, and available resources, Hardy, Olson [10] recommend a tiered, prevention-based approach to neuropsychological assessment of children at risk for neurocognitive problems due to their medical conditions. The authors suggest universal monitoring at the first level of assessment, consisting of batteries that are short (completed in less than $30 \mathrm{~min}$ ), psychometrically sound, and comprised entirely of computer-based tasks or parent-report instruments. [10] Among pediatric leukemia and brain tumor survivors, parent-report measures have demonstrated good specificity, but showed low sensitivity in identifying those with neurocognitive or psychosocial problems or those demonstrating real-life difficulties, e.g., receiving special education services. [11] [12] In contrast, Bull, Liossi [13] showed moderate to high sensitivity in using a combination of parent-, self-, and teacher-completed reports to identify those brain tumor survivors with below average IQ. These patients, however, had a particularly high prevalence of poor neurocognitive outcomes, and it is unclear if these findings generalize to survivors with a range of less severe neuropsychological difficulties.

Computerized testing is poised to be an excellent monitoring tool given its efficiency, reduced practice effects that allow more frequent evaluation and lower level of required clinical expertise for administration. In comparison to traditional neuropsychological testing, computer batteries are considerably shorter in duration, e.g., minutes versus hours, and can be more standardized in delivery. For tests of attention and processing speed, a multitude of precisely measured data can be acquired in short periods of time as stimuli can be presented rapidly and responses recorded to the millisecond, also increasing the sensitivity of the measure. Further, the data are computer-scored, thus reducing error, and administration does not usually require a doctoral-level clinician but a technician familiar with the system. [14] Computerized tests that are quick to deliver, contain multiple forms, and do not require rule learning can minimize practice effects. Some computer platforms, like CogState, were designed with the goal of repeated assessment, to detect accurately change over time and have been demonstrated to effectively minimize practice effects. [15-17] Previous studies of CogState in HIV-infected, schizophrenia, and multiple sclerosis patient groups have established its validity in children and adults, producing results comparable to traditional neuropsychological measures. [18, 19] It is currently being used in several COG trials at over 150 sites to measure the neurocognitive effects in children undergoing treatment for high-risk acute lymphoblastic leukemia (ALL) and acute promyelocytic leukemia (COG AALL1131 and AAML1331).

The validity of monitoring batteries in pediatric oncology has typically been measured by assessing their association with performance on other traditional neuropsychological tests; however, these tests may not capture well real-world functioning. [20, 21] Measures of academic performance are clinically meaningful, but infrequently utilized because of difficulty in obtaining results. [22] Further, many standardized assessments compare students' performance to one another, rather than to an a priori established benchmark that indicates whether or not a student is meeting educational standards from a particular geographic area. Using a criterion-based measure at the state-level should have good ecological validity and best assess achievement in the child's natural environment.

Childhood cancer survivors treated with chemotherapy, neurosurgery, or CNS-directed therapies are at varied risk for neurocognitive problems. [23-26] We intend to test the hypothesis that at least one of three methods: 1) Computerized assessment, CogState; 2) Questionnaire, Behavior Rating Inventory of Executive Function (BRIEF), Parent Form or Adult Version; and/or 3) Combined questionnaire and computerized assessment will be associated with reading and mathematics performance on state-administered criterion-referenced tests of reading and mathematics with adequate sensitivity and specificity to be used as neurocognitive monitoring tools. An exploratory aim of this study is to determine the cut-off scores that yield the best sensitivity and specificity.

\section{Methods \\ Participants}

Patients $\geq 8$ years of age at evaluation and $\leq 18$ years at cancer diagnosis were eligible for participation if they were English-speaking and treated with chemotherapy, cranial radiation, and/or neurosurgery. Additional eligibility criteria included $\geq 2$ years elapsed from diagnosis; no pre-cancer diagnosis of learning disabilities, developmental conditions, and/or Attention-Deficit/Hyperactivity 
Disorder; and available results from state-administered achievement testing completed after the cancer diagnosis and within 5 years of participation in the present study. Between October 2012 through July 2013, research assistants enrolled 45 patients who arrived at the outpatient clinic for a routine visit (not for chemotherapy or acute illness). Signed informed consent was obtained from all patients or their parents as appropriate for age. Participants received a $\$ 20$ honorarium. All study procedures were approved by the ethics review board at Yale University.

\section{Measures}

A demographic questionnaire with items about race and maternal education was completed by parents of patients under age 18 or adult patients.

The BRIEF-Parent Form or BRIEF-Adult Version was completed by patients under age 18 or adult patients, respectively. [27] The BRIEF is validated for adults and parent proxy to yield eight scales from 75 to 86 items. These measures have high internal consistency ( $\alpha$ 's $=.80-.98)$ and test-retest reliability $(r s=.82)$. [27] The questionnaire takes approximately 10 to $15 \mathrm{~min}$ to complete. The Metacognition Index, a composite scale assessing the ability to initiate activity, sustain working memory, organize materials, monitor, and plan/organize was used in the analysis. The authors report that T-scores $\geq 65$ (i.e., 1.5 standard deviation above the mean) indicate clinically significant symptomology, a cutoff which was adopted to define a patient "at-risk" in this study. [27]

Trained research assistants administered three $\operatorname{Cog}$ State (version 7) tasks which takes approximately 10 to 15 min to complete in total: Detection, a test of processing speed; Identification, a test of attention; and One Back, a test of working memory. These tests assess domains of cognition typically affected by cancer treatment [28-30] and was adapted from the battery used in the multi-site COG study for children with high-risk ALL (COG AALL1131). [31] The CogState Composite was calculated by converting the average raw score to an age-referenced $\mathrm{z}$-score using normative data provided by CogState. A Composite Score of $\mathrm{z}<-1$ (i.e., 1 standard deviation below the mean) was identified as performance in the "at-risk" range as determined by exploratory analysis (please refer to the Analysis and Results sections for additional information).

Results from the reading and mathematics portions of the Connecticut Mastery Test (administered to all children in grades 3 through 8) or the Connecticut Academic Performance Test (administered to all children in grade 10) were used as outcomes. These are criterion-referenced measures of academic achievement administered by the State of Connecticut's Department of Education to all students attending public schools between 1985 and 2015 .
This was the only academic measure universally administered to all students in the state at this time. Students' performance is evaluated against pre-determined achievement standards. Individual scores fall into 1 of 5 categories: Advanced, Goal, Proficient, Basic, and Below Basic. The latter 3 categories are considered to fall within the Below Goal range. For the purpose of this study, these guidelines were adopted and each participant's performance on reading and mathematics was categorized dichotomously as meeting (Goal, Advanced) or not meeting (Proficient, Basic, Below Basic) the state-defined benchmark. [32]

\section{Statistical analysis}

Descriptive statistics were calculated for the participant characteristics, performance on CogState, and results of the BRIEF. We calculated sensitivity, specificity, positive predictive power (PPV), and negative predictive power (NPV) statistics for scores in the at-risk range (see definitions above) for the BRIEF Metacognition Index (MCI) and the CogState Composite score separately and then in combination (i.e. impairment by either or both tools) for the outcomes of "meet" or "did not meet" reading and mathematics benchmarks from academic testing. The cutoff used for CogState was determined thorough exploratory analysis. We calculated sensitivity and specificity statistics using cutoffs corresponding to $1,1.5$, and 2 standard deviation from the mean CogState score for the academic outcomes. We selected the CogState cutoff that provided the best associations with the academic outcomes for the main analysis. All analyses were conducted in SAS version 9.4.

\section{Results}

\section{Participants}

One-hundred-eleven patients were approached as part of a larger study. There was no statistical difference in age, race/ethnicity, gender or diagnosis between those participants that enrolled and the 5 that declined to participate. Among the 45 participants that had available state achievement testing and thus met eligibility criteria for this study (Table 1), the mean age at evaluation was 14.0 years $(\mathrm{SD}=3.0$; range: $8.6-20.8)$ with a mean age at diagnosis of 7.1 years $(\mathrm{SD}=4.4$; range: $0.2-14.1)$. Four participants were 18 years or older. Seventy-one percent of participants were male and $51 \%$ reported their race/ ethnicity as non-Hispanic white. Diagnoses included leukemia (57.8\%), lymphoma (8.9\%), central nervous system (CNS) neoplasm (20.0\%) and other solid tumors (13.3\%). Parent- or self-report of executive functioning, as well as scores on the performance-based computerized tasks fell within the average range (Table 2). State achievement testing was completed a median of 0.73 years (range - $0.32-4.2$ ) before completion of CogState. Median time elapsed between diagnosis date and school 
Table 1 Participant Characteristics (Total $N=45$ )

\begin{tabular}{|c|c|}
\hline & Counts (\%) or Means (SD, range) \\
\hline Age at diagnosis (years) & $7.1(4.4,0.2-14.1)$ \\
\hline Age at evaluation (years) & $14.0(3.0,8.6-20.8)$ \\
\hline Time elapsed since diagnosis (years) & $6.9(3.5,2.2-16.0)$ \\
\hline \multicolumn{2}{|l|}{ Sex } \\
\hline Male & $32(71.1)$ \\
\hline Female & $13(28.9)$ \\
\hline \multicolumn{2}{|l|}{ Maternal education: ${ }^{a}$} \\
\hline High school or less & $12(27.3)$ \\
\hline $\begin{array}{l}\text { Training after high school/ some college } \\
\text { College grad or post-grad training }\end{array}$ & $\begin{array}{l}11(25.0) \\
21(47.7)\end{array}$ \\
\hline \multicolumn{2}{|l|}{ Diagnosis: } \\
\hline Leukemia & $26(57.8)$ \\
\hline Lymphoma & $4(8.9)$ \\
\hline Central nervous system neoplasm & $9(20.0)$ \\
\hline Other ${ }^{b}$ & $6(13.3)$ \\
\hline \multicolumn{2}{|l|}{ Treatment: } \\
\hline Intrathecal chemotherapy & $27(61.3)$ \\
\hline Cranial radiation, including total body & $10(22.2)$ \\
\hline Central nervous system surgery & $8(17.8)$ \\
\hline Stem cell transplant & $5(11.1)$ \\
\hline
\end{tabular}

${ }^{a}$ Category does not sum to 45 due to unanswered questions; ${ }^{\text {}}$ These included rhabdomyosarcoma [2], retinoblastoma [1], germinoma [1], Langerhans cell histiocytosis [1], neuroblastoma [1]

testing was 5.7 years (range 0.78-13.86). Two patients completed academic testing within 1 year of diagnosis.

\section{Associations between monitoring measures and academic outcomes}

At risk scores on the BRIEF-MCI were associated with poor sensitivity for below-grade level reading (26\%) and mathematics $(41 \%)$ performance (Table 3). In contrast, at-risk results on the BRIEF-MCI was associated with adequate to good specificity for below-grade level reading (88\%) and mathematics (96\%) performance. Positive predictive value (PPV) and negative predictive value (NPV) were 63 and 61\% respectively for below-grade level reading and improved to 88 and $71 \%$ respectively for below-grade level mathematics.

At-risk scores on the CogState Composite score was associated with low sensitivity for below-grade level reading (26\%) and mathematics (29\%) performance. It yielded strong specificity for reading (92\%) and mathematics (92\%) outcomes. PPV is $71 \%$ for both reading and math performance. NPV is 62 and $66 \%$ for reading and math, respectively.

With the same criteria as used previously, at risk results on either the BRIEF-MCI or CogState Composite

Table 2 Peformance on neurocognitive and academic measures

\begin{tabular}{lll}
\hline Measure & Mean (SD, range) & ${\text { Percent patients in at risk }{ }^{\mathrm{d}} \text { range }}^{\text {CogState }^{\mathrm{a}}}$ \\
$\quad$ Detection & $102.9(15.2,54.5-119.5)$ & - \\
$\quad$ Identification & $104.6(11.5,75.7-123.3)$ & - \\
$\quad$ One-Back & $95.6(12.0,74.1-118.5)$ & - \\
CogState Composite & $0.3(1.1,-2.8-1.8)$ & 16 \\
BRIEF Metacognition Index $^{\mathrm{c}}$ & $54.3(12.8,30.0-83.0)$ & 18 \\
CT Mastery Test Reading & - & 42 \\
CT Mastery Test Mathematics & - & 40
\end{tabular}

a Standard scale score, Mean $=100, S D=15 ;{ }^{b} Z$-score, Mean $=0, S D=1 ;{ }^{c}$ T-score, Mean $=50, S D=10 ;{ }^{d}$ Cutoff 1 SD below the mean (CogState) or $1.5 \mathrm{SD}$ above the mean (BRIEF) 
Table 3 Sensitivity, specificity, positive predictive power, and negative predictive power associated with using impairment on neurocognitive measures to predict rates of below grade level academic performance

\begin{tabular}{|c|c|c|c|c|c|c|c|c|}
\hline \multirow[b]{2}{*}{$\begin{array}{l}\text { Neurocognitive } \\
\text { Measure, Cutoff }\end{array}$} & \multicolumn{4}{|c|}{ Reading below grade level } & \multicolumn{4}{|c|}{ Mathematics below grade level } \\
\hline & $\begin{array}{l}\text { Sensitivity, } \\
\%(95 \% \text { Cl) }\end{array}$ & $\begin{array}{l}\text { Specificity, } \\
\%(95 \% \text { Cl) }\end{array}$ & $\begin{array}{l}\text { Positive } \\
\text { Predictive Value, } \\
\%(95 \% \mathrm{Cl})\end{array}$ & $\begin{array}{l}\text { Negative } \\
\text { Predictive Value, } \\
\%(95 \% \mathrm{Cl})\end{array}$ & $\begin{array}{l}\text { Sensitivity, } \\
\%(95 \% \text { Cl) }\end{array}$ & $\begin{array}{l}\text { Specificity, } \\
\%(95 \% \text { Cl) }\end{array}$ & $\begin{array}{l}\text { Positive } \\
\text { Predictive Value, } \\
\%(95 \% \text { Cl) }\end{array}$ & $\begin{array}{l}\text { Negative } \\
\text { Predictive Value, } \\
\%(95 \% \mathrm{Cl})\end{array}$ \\
\hline BRIEF-MCI, T $\geq 65$ & $26(7-46)$ & $\begin{array}{l}88(75- \\
100)\end{array}$ & $63(29-96)$ & $61(45-77)$ & $41(18-65)$ & $\begin{array}{l}96(88- \\
100)\end{array}$ & $88(65-100)$ & $71(55-86)$ \\
\hline $\begin{array}{l}\text { CogState Composite, } \\
z<-1\end{array}$ & $26(7-46)$ & $\begin{array}{l}92(81- \\
100)\end{array}$ & $71(38-100)$ & $62(47-78)$ & $29(8-51)$ & $\begin{array}{l}92(81- \\
100)\end{array}$ & $71(38-100)$ & $66(38-100)$ \\
\hline $\begin{array}{l}\text { BRIEF-MCI, T } \geq 65 \text { or } \\
\text { CogState Composite, } \\
z<-1\end{array}$ & $47(25-70)$ & $84(70-98)$ & $69(44-94)$ & $68(51-84)$ & $59(35-82)$ & $\begin{array}{l}88(75- \\
100)\end{array}$ & $77(54-100)$ & $76(60-91)$ \\
\hline
\end{tabular}

BRIEF-MCI = Behavior Rating Inventory of Executive Function, Metacognition Index

or both was associated with low sensitivity for below grade level reading (47\%) and mathematics (59\%). At risk results on at least one of these measures was associated with better specificity for below grade level reading (84\%) and mathematics (88\%). But similar to using either measure alone, PPV was 69 and $77 \%$ for reading and math respectively.

In the analysis presented above, the CogState cutoff of $\mathrm{z}$ $<-1$ was used to identify participants in the at-risk range because exploratory analysis indicated that the cutoff produced the best sensitivity and specificity, relative to cutoffs of 1.5 and 2 SD from the mean score. For example, when using a cutoff of $\mathrm{z}<-1.5$ (1 SD below the mean) for the CogState Composite, sensitivity was reduced to $18 \%$ (from $26 \%$ ) and specificity was improved to $96 \%$ (from $92 \%$ ) for reading outcomes. For the combined analysis using a CogState Composite cutoff of $\mathrm{z}<-1.5$ with the BRIEF-MCI cutoff of $\mathrm{T} \geq 65$ yielded slightly improved specificity for reading (88\% compared to $84 \%$ ) and mathematics $(92 \%$ compared to $88 \%$ ) outcomes.

\section{Discussion}

We aimed to determine if three potential universal monitoring plans using short questionnaires and/or computer assessments would identify those pediatric cancer survivors demonstrating academic weaknesses on state-administered assessments. The results indicate that impairment on the BRIEF-parent or adult-version and CogState computerized assessment demonstrated high specificity, but low sensitivity in classifying those individuals who did not meet academic benchmarks. Combining these measures did not improve sensitivity significantly and mildly reduced specificity. That is, at-risk results on either or both screening measures were not more highly associated with academic impairment.

This study is unique in utilizing a uniformly delivered criterion-referenced standard of educational attainment used within the State of Connecticut. In part, these data are used by school systems to identify those children who need additional support and intervention. As such they are a meaningful indicator of a student's success in the subject areas of reading and mathematics. Our data indicate that participants who show at-risk results on either monitoring measure are likely to demonstrate deficiencies in academic achievement. These measures can appropriate resources to individuals in need of comprehensive neurocognitive assessment. However, it is important to note that with poor sensitivity and low negative predictive value (NPV) the BRIEF-MCI and CogState Composite computerized assessment will not detect many pediatric cancer survivors that could benefit from comprehensive evaluation. Thus, if a patient were not identified by the BRIEF-MCI or CogState Composite, it would be incorrect to assume that they did not need additional testing. In terms of identifying children at risk for neurocognitive weaknesses, an ideal screening tool would not miss as many children in need of assessment.

These results are consistent with two other studies that have investigated the use of parent-report measures as surveillance tools for identification of pediatric leukemia and brain tumor survivors with neurocognitive or learning problems $[11,12]$. As in the current study, these measures had good specificity but were not sensitive enough to identify survivors with negative outcomes. Specifically, among pediatric leukemia and brain tumor survivors, screening for attention problems using parent-report measures (e.g., Conners Parent Rating Scale and the Child Behavior Checklist) demonstrated good specificity but showed low sensitivity in identifying those with either lower IQ or diminished working memory or information processing speed. [11] Similarly, in another study parent-completed BRIEF questionnaires demonstrated good specificity, but results were not sensitive enough to identify those leukemia survivors demonstrating real-life difficulties in the form of receiving special education services or problems with attention. [12]

These results indicate that it will be important to identify other monitoring tools with good sensitivity to identify those patients with neurocognitive difficulties. There is ongoing work to create and validate standardized computerized assessments of cognition, given their 
portability, reduced administration time, and ease of administration. Computerized tests, including CogState, require a computer, internet access, and qualified staff (several hours of training). There is a cost to CogState (https://www.cogstate.com), like many other computer platforms; however, this is substantially less than the cost of a neuropsychological evaluation or the time of a neuropsychologist. Psychological expertise is not required to administer these tests, but interpretation of the data should be completed by a specialist. Overall, however, there is potentially a savings in professional time and cost that can be advantageous in smaller institutions with less resources. [33-35] Other computerized batteries include the NIH toolbox for the Assessment of Neurological and Behavioral Function, [35] which is being utilized in both cancer [36] and non-cancer populations. [37] Similarly, numerous other computerized batteries, such as the Cambridge Neuropsychological Test Automated Battery (CANTAB) [38], Comprehensive Instrument for Evaluating Mild Traumatic Brain Injury (CIEMTBI) [33], and Immediate Post-Concussion Assessment and Cognitive Testing (ImPACT) [39] are being used to test cognition quickly and reliably among those with traumatic brain injury, CNS tumor, and mental health disorders.

A comprehensive history gathered through clinical interview and/or a review of the medical record can increase the sensitivity of surveillance [40]. A thorough history may include questions of patients, family, and/or teachers about grades earned, classroom behaviors, and performance. It is noted, however, that there is often low concordance between teacher- and parent-report and performance-based measures among pediatric cancer survivors. [41, 42] Brain tumor survivors are also more likely to under-report problems. [43] This is concerning as cognitive problems may go undetected in this high-risk population if we rely solely on self- and/or proxy-report to prompt comprehensive testing, which ultimately can delay intervention. Longer batteries that combine traditional neuropsychological performance-based measures with parent-proxy [44] have shown good ability to identify those with academic problems on nationally normed tests of achievement. However, these methods may not be standardized across settings or interviewers and may require more time and expertise than is available.

This study should be considered in the context of certain limitations. The sample size is small and represents participants from only one tertiary care center. Moreover, because a state-specific assessment was used, these results are most relevant to the state and limit generalizability. However, it may also be viewed as a strength of the study. Because academic performance varies among states, the best criteria for evaluating academic achievement would derive from expectations specific to the childhood cancer survivor's educational environment. Additionally, this study only examined cancer survivors who were at least 2 years from diagnosis rather than earlier in the therapy period so generalizations to these patients cannot be made. It should be noted that 2 participants completed academic testing within 1 year of diagnosis, which would potentially miss neurocognitive effects that emerge later. Because these 2 participants showed agreement between academic testing and the later completed study assessments, it would not have appeared to affect the data. Academic achievement is increasingly recognized as an important clinical outcome [45]; however, the association between performance on neurocognitive domains such as attention and working memory and academic achievement is not as strong as a measure of overall ability such as IQ [46]. It may be promising to examine other downstream measures that are associated with neurocognitive issues, such as educational attainment; however, the length of follow up did not allow for that in this particular study [47]. Additionally, most participants (92\%) exhibited adequate abilities in the areas tested, e.g., executive functioning, attention, working memory, and processing speed so the relatively small sample size of the present study may result in poor sensitivity. These potential monitoring tools may have stronger specificity in patients at highest risk for neurocognitive deficits (e.g., brain tumor patients), although these are individuals who may be the most appropriate for comprehensive evaluation based on their diagnosis and treatment alone.

\section{Conclusion}

With increasing numbers of pediatric cancer survivors, it will be important to have an easily and quickly administered monitoring tool, particularly in resource-limited communities, to identify those patients in need of comprehensive neurocognitive assessment. While individuals identified from the BRIEF-MCI or CogState Composite would likely benefit from a full neuropsychological evaluation given the strong specificity, use of these measures as screening tools is limited. They do not identify many patients with academic difficulties and in need of a full neuropsychological evaluation. Continued effort is required to find screening measures that have both strong sensitivity and specificity.

\section{Abbreviation}

BRIEF-MCl: Behavior Rating Inventory of Executive Function - Metacognition Index; COG: Children's Oncology Group

\section{Acknowledgements}

Not applicable.

\section{Funding}

This research was supported by a Scholars Award from the St. Baldrick's foundation to NKL. CogState software was provided to the investigators 
without cost for use in the study. However, CogState had no role in the design, conduct, or analysis of the study.

\section{Availability of data and materials}

The datasets used and analysed during the current study are available from the corresponding author on reasonable request.

\section{Authors' contributions}

LB contributed to the study conception and design, collected data, and drafted the manuscript; HRM and WR contributed to the study design, collected data, and completed the statistical analysis; CM contributed to the study conception and design; KKH contributed to the study conception and design and collected data; NKL contributed to the study conception and design and drafted the manuscript. All authors critically reviewed the manuscript. All authors read and approved the final manuscript.

\section{Ethics approval and consent to participate}

This study was approved by the Human Investigation Committee at Yale University. Signed informed consent was obtained from all patients or their parents as appropriate for age.

\section{Consent for publication}

Not applicable.

\section{Competing interests}

The authors declare that they have no competing interests.

\section{Publisher's Note}

Springer Nature remains neutral with regard to jurisdictional claims in published maps and institutional affiliations.

\section{Author details}

${ }^{1}$ Yale University School of Medicine, 15 PO Box 208064, 16333 Cedar Street, LMP-2073 (for courier mail), 17, New Haven, CT 06520-8064, USA. ${ }^{2}$ University of Miami, Coral Gables, FL, USA. ${ }^{3}$ School of Public Health, University of California, Berkeley, California, USA. ${ }^{4}$ Center for Neuroscience and Behavioral Medicine, Neuropsychology Division, Children's National Medical Center, Washington, DC, USA. ${ }^{5}$ Department of Psychiatry and Behavioral Science, George Washington University School of Medicine, Washington, DC, USA

${ }^{6}$ Yale Cancer Center, New Haven, CT, USA.

\section{Received: 26 November 2018 Accepted: 15 April 2019}

\section{Published online: 02 May 2019}

\section{References}

1. Pui CH, Gajiar AJ, Kane JR, Qaddoumi IA, Pappo AS. Challenging issues in pediatric oncology. Nat Rev Clin Oncol. 2011;8(9):540-9.

2. Winick N. Neurocognitive outcome in survivors of pediatric cancer. Curr Opin Pediatr. 2011;23(1):27-33.

3. American Academy of Pediatrics Section on Hematology/Oncology Children's Oncology G. Long-term follow-up care for pediatric cancer survivors. Pediatrics. 2009;123(3):906-15.

4. Group UKCSCSGLE. Therapy based long term follow up practice statement. 2005

5. Wallace WH, Thompson L, Anderson RA. Long term follow-up of survivors of childhood cancer: summary of updated SIGN quidance. BMJ. 2013;346:f1190.

6. Howell DHT, Oliver TK, Chulak T, Mayo S, Aubin M, Chasen M, Earle CC, Friedman AJ, Green E, Jones GW, Jones JM, Parkinson M, Payeur N, Sabiston CM, Sinclair S, Tompson M. A pan-Canadian practice guideline panCanadian guidance on organization and structure of survivorship services and psychosocial-supportive care best practices for adult Cancer survivors. Toronto: Canadian Partnership Against Cancer (Cancer Journey Action Group) and the Canadian Association of Psychosocial Oncology; 2011.

7. Walsh KS, Noll RB, Annett RD, Patel SK, Patenaude AF, Embry L. Standard of Care for Neuropsychological Monitoring in pediatric neurooncology: lessons from the Children's oncology group (COG). Pediatr Blood Cancer. 2016:63(2):191-5.

8. Jameson JP, Blank MB. The role of clinical psychology in rural mental health services: Defining problems and developing solutions. Clin Psychol Sci Pract. 2007;14(3):283-98
9. Lai JS, Zelko F, Krull KR, Cella D, Nowinski C, Manley PE, et al. Parentreported cognition of children with cancer and its potential clinical usefulness. Qual Life Res. 2014;23(4):1049-58.

10. Hardy KK, Olson K, Cox S, Kennedy T, Walsh KW. Systematic review: A prevention-based model of neuropsychological assessment for children with medical illness. J Pediatric Psyc. 2017;42(8):815-822.

11. Hardy KK, Willard WW, Wigdor AB, Allen TM, Bonner MJ. The potential utility of parent-reported attention screening in survivors of childhood cancer to identify those in need of comprehensive neuropsychological evaluation. Neurooncol Pract. 2015;2(1):32-9.

12. Viola A, Balsamo L, Neglia JP, Brouwers P, Ma X, Kadan-Lottick NS. The behavior rating inventory of executive function (BRIEF) to identify pediatric acute lymphoblastic leukemia (ALL) survivors at risk for neurocognitive impairment. J Pediatr Hematol Oncol. 2017;39(3):174-8.

13. Bull KS, Liossi C, Peacock JL, Yuen HM, Kennedy CR, Children's C, et al. Screening for cognitive deficits in 8 to 14-year old children with cerebellar tumors using self-report measures of executive and behavioral functioning and health-related quality of life. Neuro-Oncology. 2015;17(12):1628-36.

14. Wild K, Howieson D, Webbe F, Seelye A, Kaye J. Status of computerized cognitive testing in aging: a systematic review. Alzheimers Dement. 2008;4(6):428-37.

15. Falleti MG, Maruff P, Collie A, Darby DG. Practice effects associated with the repeated assessment of cognitive function using the CogState battery at 10-minute, one week and one month test-retest intervals. J Clin Exp Neuropsychol. 2006;28(7):1095-112.

16. Kral TV, Heo M, Whiteford LM, Faith MS. Effects on cognitive performance of eating compared with omitting breakfast in elementary schoolchildren. J Dev Behav Pediatr. 2012:33(1):9-16.

17. Mollica CM, Maruff P, Collie A, Vance A. Repeated assessment of cognition in children and the measurement of performance change. Child Neuropsychology. 2005;11(3):303-10.

18. Yamashita Y, Mukasa A, Anai C, Honda Y, Kunisaki C, Koutaki J, et al. Summer treatment program for children with attention deficit hyperactivity disorder: Japanese experience in 5 years. Brain Dev. 2011:33(3):260-7.

19. Maruff $P$, Thomas E, Cysique L, Brew B, Collie A, Snyder $P$, et al. Validity of the CogState brief battery: relationship to standardized tests and sensitivity to cognitive impairment in mild traumatic brain injury, schizophrenia, and AIDS dementia complex. Arch Clin Neuropsychol. 2009;24(2):165-78.

20. Olson K, Jacobson KK, Van Oot P. Ecological validity of pediatric neuropsychological measures: current state and future directions. Appl Neuropsychol Child. 2013;2(1):17-23.

21. Silver $\mathrm{CH}$. Ecological validity of neuropsychological assessment in childhood traumatic brain injury. J Head Trauma Rehabil. 2000;15(4):973-88.

22. Harshman LA, Barron S, Button AM, Smith BJ, Link BK, Lynch CF, et al. Population-based exploration of academic achievement outcomes in pediatric acute lymphoblastic leukemia survivors. J Pediatr Psychol. 2012;37(4):458-66.

23. Nathan PC, Patel SK, Dilley K, Goldsby R, Harvey J, Jacobsen C, et al. Guidelines for identification of, advocacy for, and intervention in neurocognitive problems in survivors of childhood cancer: a report from the Children's oncology group. Arch Pediatr Adolesc Med. 2007;161(8):798-806

24. Kadan-Lottick NS, Zeltzer LK, Liu Q, Yasui Y, Ellenberg L, Gioia G, et al. Neurocognitive functioning in adult survivors of childhood non-central nervous system cancers. J Natl Cancer Inst. 2010;102(12):881-93.

25. Matsos A, Loomes M, Zhou I, Macmillan E, Sabel I, Rotziokos E, et al. Chemotherapy-induced cognitive impairments: white matter pathologies. Cancer Treat Rev. 2017;61:6-14

26. Vitali M, Ripamonti Cl, Roila F, Proto C, Signorelli D, Imbimbo M, et al. Cognitive impairment and chemotherapy: a brief overview. Crit Rev Oncol Hematol. 2017;118:7-14

27. Gioia GA, Isquith PK, Guy SC, Kenworthy L. Behavior rating inventory of executive function. Child Neuropsychol. 2000;6(3):235-8.

28. Campbell LK, Scaduto M, Sharp W, Dufton L, Van Slyke D, Whitlock JA, et al. A meta-analysis of the neurocognitive sequelae of treatment for childhood acute lymphocytic leukemia. Pediatr Blood Cancer. 2007:49(1):65-73.

29. Anderson FS, Kunin-Batson AS. Neurocognitive late effects of chemotherapy in children: the past 10 years of research on brain structure and function. Pediatr Blood Cancer. 2009;52(2):159-64

30. Butler RW, Haser JK. Neurocognitive effects of treatment for childhood cancer. Ment Retard Dev Disabil Res Rev. 2006;12(3):184-91.

31. Hardy KKWN, Hostetter SA, Harel BT, Walsh KS, Annett RD, Embry L, Burke MJ, Salzer WL, Noll RB. Promoting neurocognitive assessment participation 
in a large, multi-site treatment study of children with newly diagnosed acute lymphoblastic leukemia: a Children's oncology group study AALL1131. In: Poster presented at the 2014 American Academy of Pediatrics conference and exhibition. San Diego, CA; 2014.

32. Hayes J. Connecticut Mastery Tests's Measurement of Grade Level Skills. 2010 Contract No.: 2010-R-0167.

33. Borges A, Raab S, Lininger M. A comprehensive instrument for evaluating mild traumatic brain injury (Mtbi)/concussion in independent adults: a pilot study. Int J Sports Phys Ther. 2017;12(3):381-9.

34. Collie A, Darby D, Maruff P. Computerised cognitive assessment of athletes with sports related head injury. Br I Sports Med. 2001;35(5):297-302

35. Weintraub S, Dikmen SS, Heaton RK, Tulsky DS, Zelazo PD, Bauer PJ, et al. Cognition assessment using the $\mathrm{NIH}$ toolbox. Neurology. 2013;80(11 Supplement 3):S54-64.

36. Lang S, Cadeaux M, Opoku-Darko M, Gaxiola-Valdez I, Partlo LA, Goodyear $B G$, et al. Assessment of cognitive, emotional, and motor domains in patients with diffuse gliomas using the National Institutes of Health toolbox battery. World Neurosurg. 2017;99:448-56.

37. Carlozzi NE, Goodnight S, Casaletto KB, Goldsmith A, Heaton RK, Wong AW, et al. Validation of the NIH toolbox in individuals with neurologic disorders. Arch Clin Neuropsychol. 2017;32(5):555-73.

38. Frias A, Dickstein DP, Merranko J, Gill MK, Goldstein TR, Goldstein Bl, et al. Longitudinal cognitive trajectories and associated clinical variables in youth with bipolar disorder. Bipolar Disord. 2017;19(4):273-84.

39. Farnsworth IL II, Dargo L, Ragan BG, Kang M. Reliability of computerized neurocognitive tests for concussion assessment: a metaanalysis. J Athl Train. 2017.

40. Ramirez Basco M, Bostic JQ, Davies D, Rush AJ, Witte B, Hendrickse W, et al. Methods to improve diagnostic accuracy in a community mental health setting. Am J Psychiatry. 2000;157(10):1599-605.

41. Willard WW, Conklin HM, Huang L, Zhang H, Kahalley LS. Concordance of parent-, teacher- and self-report ratings on the Conners 3 in adolescent survivors of cancer. Psychol Assess. 2016;28(9):1110-8.

42. Howarth RA, Ashford JM, Merchant TE, Ogg RJ, Santana V, Wu S, et al. The utility of parent report in the assessment of working memory among childhood brain tumor survivors. J Int Neuropsychol Soc. 2013;19(4):380-9.

43. O'Leary TE, Diller L, Recklitis CJ. The effects of response bias on self-reported quality of life among childhood cancer survivors. Qual Life Res. 2007;16(7):1211-20.

44. Krull KR, Okcu MF, Potter B, Jain N, Dreyer Z, Kamdar K, et al. Screening for neurocognitive impairment in pediatric cancer long-term survivors. J Clin Oncol. 2008;26(25):4138-43.

45. Tabor E. FDA requirements for clinical studies in pediatric patients. Regulatory Focus. 2009;14:16-21.

46. Mayes SD, Calhoun SL, Bixler EO, Zimmerman DN. IQ and neuropsychological predictors of academic achievement. Learn Individ Differ. 2009;19:238-41.

47. Mitby PA, Robison LL, Whitton JA, Zevon MA, Gibbs IC, Tersak JM, et al. Utilization of special education services and educational attainment among long-term survivors of childhood cancer: a report from the childhood Cancer survivor study. Cancer. 2003:97(4):1115-26.

Ready to submit your research? Choose BMC and benefit from:

- fast, convenient online submission

- thorough peer review by experienced researchers in your field

- rapid publication on acceptance

- support for research data, including large and complex data types

- gold Open Access which fosters wider collaboration and increased citations

- maximum visibility for your research: over $100 \mathrm{M}$ website views per year

At BMC, research is always in progress.

Learn more biomedcentral.com/submissions 